\title{
Sistema respiratório de Amphisbaena vermicularis e Amphisbaena microcephala (Squamata, Amphisbaenia, Amphisbaenidae)
}

\author{
Maria Eliana C. Navega-Gonçalves ${ }^{1} \&$ José Roberto M. C. da Silva $^{2,3}$ \\ 1. Faculdade de Ciências Exatas e da Natureza, Universidade Metodista de Piracicaba, Rodovia do Açúcar, Km 156, 13400-911, Piracicaba, SP, Brasil. (eliana.navega@gmail.com) \\ 2. Departamento de Biologia Celular e do Desenvolvimento, Instituto de Ciências Biomédicas, Universidade de São Paulo, Av. Prof. Lineu Prestes, 1524, sala 411, 05508-900, São Paulo, SP, \\ Brasil. (jrmcs@usp.br) \\ 3. Centro de Biologia Marinha (CEBIMar), Universidade de São Paulo.
}

\begin{abstract}
Respiratory system of Amphisbaena vermicularis and Amphisbaena microcephala (Squamata, Amphisbaenia,Amphisbaenidae). The macroscopic and microscopic morphology of the trachea and lungs of Amphisbaena vermicularis Wagler, 1824 and Amphisbaena microcephala (Wagler, 1824), as well as the ultrastructure of the pulmonary respiratory chambers of the latter, are described for the first time. The trachea does not ramify, and its caudal segment, between the lungs, was named bronchus. The left lung is long, sac-like and unicameral, with a faveolar parenchyma in the cranial portion and a trabecular parenchyma in the caudal portion. Respiratory chambers are present in both regions of the lungs and it is suggested that the caudal portion acts as a reservoir of air. The right lung is reduced in both species, however in A. vermicularis this reduction is fairly pronounced and only a vestige of this organ can be observed, but in $A$. microcephala the right lung is a delimited organ that links to the caudal portion of the tracheal tube through two holes. Pneumocytes I and II occur in the respiratory chambers. The basal membranes of the pneumocytes I and of the endothelial cells are fused, diminishing the air-to-blood barrier which measures approximately $0.5 \mu \mathrm{m}$ in A. microcephala. Morphological features described in this paper may represent some adaptations that permit the survival of the specimens of Amphisbaenia in the subterranean galleries where they spend most of their lives, under conditions of low air renewal, relatively variable levels of humidity and suspended particles.
\end{abstract}

KEYWORDS. Faveolar, fossorial reptiles, lung, trachea.

RESUMO. A morfologia macro e microscópica da traqueia e pulmões de Amphisbaena vermicularis Wagler, 1824 e Amphisbaena microcephala (Wagler, 1824), assim como a ultraestrutura das câmaras respiratórias, foram descritas pela primeira vez neste estudo. A traqueia não se ramifica e seu segmento caudal, situado entre os pulmões, foi denominado brônquio. O pulmão esquerdo é alongado, saculiforme e unicameral, com parênquima faveolar na porção cranial e trabecular, na porção caudal. Câmaras respiratórias estão presentes em ambas as regiões do pulmão, mas é possível que a região caudal funcione também como reservatório de ar. O pulmão direito está reduzido nas duas espécies, no entanto em $A$. vermicularis a redução é bastante acentuada e apenas um vestígio deste órgão pode ser observado, mas em $A$. microcephala o pulmão direito é um órgão com limites definidos que se comunica com a porção caudal do tubo traqueal, através de dois orifícios. Pneumócitos tipo I e tipo II estão presentes nas câmaras respiratórias. As lâminas basais dos pneumócitos I e das células endoteliais encontram-se fundidas, de forma a diminuir a barreira ar-sangue, que é de aproximadamente $0,5 \mu \mathrm{m}$ em A. microcephala. As características morfológicas descritas neste estudo podem representar adaptações que permitem a sobrevivência dos espécimes de Amphisbaenia nas galerias subterrâneas, onde passam a maior parte de suas vidas sob condições de baixa renovação de ar, níveis de umidade relativamente variáveis e partículas em suspensão.

PALAVRAS-CHAVE. Favéolos, pulmão, répteis fossoriais, traqueia.

Amphisbaenia compõem-se de répteis fossoriais, que apresentam marcantes especializações para a vida subterrânea, dentre as quais está a construção de seus próprios sistemas de túneis através da compressão do solo no interior das galerias, com movimentos da cabeça (GANS, 1968).

Estudos referentes à fisiologia da respiração em Amphisbaenia (JOHANSEN et al., 1980; WeBER et al., 1981; Kamel \& Gatten, 1983; Abe \& Johansen, 1987; NAvas et al., 2004) têm mostrado que algumas espécies apresentam interessantes adaptações fisiológicas para a vida fossorial, incluindo alta afinidade sanguínea pelo oxigênio, concentração elevada de mioglobina nos músculos esqueléticos e cardíacos, significativa taxa de trocas gasosas através da pele, além de baixa demanda por oxigênio durante o repouso. No entanto, a morfologia do sistema respiratório é ainda pouco conhecida neste grupo, embora as primeiras descrições sejam encontradas em estudos feitos no século XIX (Meckel, 1818; Bedriaga, 1884; Smalian, 1884; MilANi, 1894; ButLER, 1895, entre outros).

A redução do pulmão direito é uma característica peculiar dos anfisbênios (BUTLER, 1895) e diferentes graus de redução foram observados em várias espécies (Gans, 1960; CrooK \& Parsons, 1980; NAVEGAGonÇALVES, 2009), embora o significado funcional desta variação permaneça desconhecido. Neste caso, a delimitação da "traqueia" e do "brônquio", bem como o uso destes termos torna-se impreciso, uma vez que o reconhecimento dos mesmos não pode ser feito na ausência de uma bifurcação da traqueia que demarque o início do brônquio no pulmão remanescente (LUCHTEL \& KARDONG, 1981).

O pulmão esquerdo, por sua vez, é alongado e saculiforme com duas regiões distintas: uma cranial com um número maior de subdivisões internas e de aspecto esponjoso e, uma caudal, com um número menor de subdivisões internas e de aspecto reticuloso (SMALIAN, 1884; NaVEGa-Gonçalves \& SouZa, 2001; NaVEGaGONÇALVES, 2009). Este tipo pulmonar é classificado como unicameral com parênquima heterogeneamente distribuído, do tipo faveolar na porção cranial e, trabecular, na porção caudal (conforme classificações adotadas por DunCKer, 1978; PERrY \& DUNCKER, 1978; PERRY, 1983).

A padronização da terminologia utilizada é 
importante para a comparação das estruturas respiratórias em répteis e uma ampla revisão sobre o assunto e algumas propostas nomenclaturais são encontradas nos trabalhos realizados por PERRY (1998) e WALLACH (1998), os quais foram considerados neste estudo.

Diante do exposto, a proposta deste estudo é contribuir para o conhecimento do sistema respiratório de Amphisbaenia, através de uma descrição morfológica dos pulmões e traqueia de duas espécies de anfisbenídeos, Amphisbaena vermicularis Wagler, 1824 e Amphisbaena microcephala (Wagler, 1824). Objetivase ainda caracterizar anátomo-histologicamente a traqueia, as regiões cranial e caudal do pulmão esquerdo e o pulmão direito e descrever a ultraestrutura das câmaras respiratórias, de forma a inferir possíveis adaptações morfológicas do trato respiratório que estejam relacionadas ao hábito fossorial destes animais.

\section{MATERIAL E MÉTODOS}

Para a realização deste estudo foram utilizados espécimes de Amphisbaena vermicularis ( $\mathrm{n}=3$ : massa $11,2 \mathrm{~g} \pm 2,0 \mathrm{~g}$ de desvio padrão; comprimento total 28,9 $\mathrm{cm} \pm 2,4 \mathrm{~cm})$ e de $A$. microcephala $(\mathrm{n}=4:$ massa $40,1 \mathrm{~g} \pm$ $16,0 \mathrm{~g}$; comprimento total $36,5 \mathrm{~cm} \pm 5,2 \mathrm{~cm}$ ), procedentes de resgates de fauna de aproveitamentos hidrelétricos (exceto um espécime de $A$. microcephala proveniente de São Paulo - SP, que foi doado ao Departamento de Zoologia do Instituto de Biociências da Universidade de São Paulo). Os espécimes de $A$. vermicularis (exceto um, que foi totalmente aproveitado para estudos histológicos) foram depositados na Coleção Zoológica da Universidade Estadual do Rio de Janeiro (UERJ) e os de A. microcephala na Coleção Zoológica da Universidade Federal do Rio de Janeiro (UFRJ) (Tab. I).

Os espécimes recebidos vivos foram eutanasiados com Ketamina $50 \mathrm{mg}$, na dose de $25 \mathrm{mg} / \mathrm{kg}$ peso do corpo, via intramuscular na região ventral do corpo (com base em CoOper, 1992 e Massone, 1999).

Para os estudos anatômicos, fez-se uma incisão crânio-caudal mediana ventral, da cloaca até a sínfise mandibular, para melhor exposição das vísceras e de sua sintopia. Incisões longitudinais da traqueia e do pulmão esquerdo foram feitas para o exame interno destes órgãos. As imagens dos pulmões, traqueia e parede interna dos

Tab. I. Dados relativos aos espécimes de Amphisbaena vermicularis Wagler, 1824 (AV) e A. microcephala (Wagler, 1824) (AM) utilizados para a realização dos estudos do sistema respiratório (C.T., comprimento total; M, massa).

\begin{tabular}{lcccc}
\hline Espécie/tombo & Procedência & Sexo & C.T. (cm) & M (g) \\
\hline AV-720-UERJ & Minaçu-GO & Fêmea & 31,6 & 13,5 \\
AV-721-UERJ & Minaçu-GO & Fêmea & 26,9 & 9,8 \\
AV (não tombado) & Minaçu-GO & Macho & 28,1 & 10,2 \\
AM-1540-UFRJ & Anaurilândia-MS & Fêmea & 28,8 & 16,9 \\
AM-1541-UFRJ & Corumbá-GO & Macho & 38,6 & 50,2 \\
AM-1542-UFRJ & São Paulo-SP & Macho & 38,4 & 41,6 \\
AM-1543-UFRJ & Corumbá-GO & Macho & 40,1 & 51,5 \\
\hline
\end{tabular}

mesmos foram obtidas com câmera fotográfica acoplada em estereomicroscópio. O material foi posteriormente fixado em formol a $10 \%$.

Para os procedimentos histológicos, os órgãos dos animais recém-mortos foram fixados em solução de McDowell a 4,0\% (McDowell \& TRUMP, 1976) durante 48 horas. Após desidratação com etanol a 95,0\%, o material foi embebido em historresina (JUNQUEIRA, 1995) e os cortes (de 2-3 micrômetros) corados com azul de toluidina $(1,0 \%)$ e fucsina ácida $(0,05 \%)$. A confirmação da presença de células mucosas foi feita através da técnica de PAS (McManus, 1946). Os tecidos preparados foram observados e fotografados sob um foto-microscópio.

Para a microscopia eletrônica, os tecidos pulmonares foram preservados em glutaraldeído a 2,0 $\%$ em tampão fosfato por aproximadamente 24 horas. Posteriormente, foram mantidos durante 45 minutos em solução de tetróxido de osmium a 1,0\%, previamente diluída em solução tamponada e, novamente lavados em solução isotônica. Em seguida foram desidratados em concentrações crescentes de etanol e colocados em óxido propileno puro. O material foi então tratado com uma mistura de óxido propileno e resina Spurr (HAYAT, 1981), na proporção de $1: 1$ por 5 horas em temperatura ambiente e mantido em resina pura por 8 horas. Finalmente, o material foi incluído em nova resina pura, em moldes de silicone. Os blocos foram então guardados em estufa a $60^{\circ} \mathrm{C}$, por 72 horas. Cortes com $250 \mathrm{~nm}$ de espessura foram feitos com a utilização de um ultramicrótomo e corados com solução de azul de toluidina a $0,2 \%$.

Após exame das secções de $250 \mathrm{~nm}$, o material foi novamente cortado para obtenção de cortes de $60 \mathrm{~nm}$, que foram depositados sobre tela de cobre (300 mesh) e contrastados com acetato de uranila $(2,0 \%)$, por 5 minutos. As secções foram lavadas em água destilada, colocadas em citrato de chumbo (REYNOLDS, 1963) e, por fim, novamente lavadas em água destilada e secas. O estudo da ultraestrutura e a documentação fotográfica foram realizados sob microscópio eletrônico no Departamento de Biologia Celular e do Desenvolvimento do Instituto de Ciências Biomédicas da Universidade de São Paulo.

\section{RESULTADOS}

Morfologia macroscópica e mesoscópica. O tubo traqueal de Amphisbaena vermicularis e de $A$. microcephala inicia-se após a glote, na região oral e, estende-se crânio-caudalmente ao longo da linha mediana da cavidade pleuroperitoneal. A parte oral da traqueia ou laringe está delimitada pelos cornos posteriores do hioide. A traqueia é ventral ao esôfago, ao qual está unido pela lâmina mesentérica esofágicatraqueal. Penetra na face medial do pulmão esquerdo em sua porção cranial, sem ramificar-se (Figs. 1, 2).

O pulmão esquerdo é alongado e saculiforme, ventral ao tubo digestório e unido ao estômago e ao fígado, respectivamente, pelos mesentérios pulmogástrico 


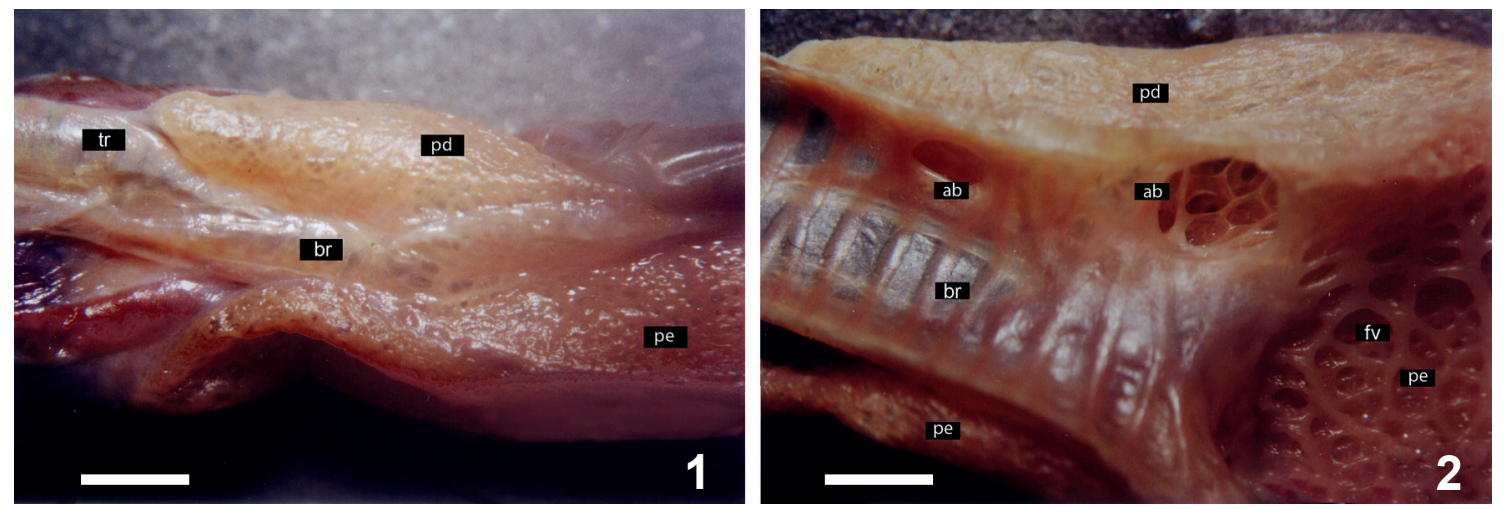

Figs 1, 2. Amphisbaena microcephala (Wagler, 1824), traqueia e pulmões em vista dorsal: 1, morfologia externa; 2, porção caudal da traqueia (brônquio) e pulmão esquerdo em secção longitudinal (ab, abertura bronquial; br, brônquio; fv, favéolos; pd, pulmão direito; pe, pulmão esquerdo; tr, traqueia). Escalas: $2,5 \mathrm{~mm}, 1,67 \mathrm{~mm}$.

e pulmo-hepático. É formado por uma única câmara (tipo unicameral), cujas paredes internas apresentam trabéculas que formam pequenas câmaras respiratórias.

Duas regiões são distintas no pulmão esquerdo: uma cranial e de aspecto esponjoso e outra caudal, semelhante a um saco membranoso. Na região cranial, que corresponde aproximadamente à metade do pulmão, o parênquima pulmonar é densamente subdividido em trabéculas primárias, secundárias e terciárias e constituído de muitas câmaras respiratórias, os favéolos, o que caracteriza um parênquima faveolar (Fig. 3). As trabéculas primárias estão em contato com o lúmen pulmonar e apresentam diâmetros maiores em relação às secundárias e terciárias, sendo as últimas de menor diâmetro e em contato com a região pleural do pulmão (Fig. 4). A região caudal é formada por um número menor de câmaras respiratórias de paredes baixas, que lembram as malhas de uma rede. Nesta, apenas as trabéculas primárias estão presentes e caracteriza um tipo de parênquima denominado trabecular (Fig. 4). Uma região de transição pode ser identificada entre a porção cranial e caudal do pulmão esquerdo, na qual se observa a perda gradativa de trabéculas, de forma que o parênquima passa de faveolar para trabecular (Fig. 5).

O pulmão direito é reduzido em ambas as espécies. Em Amphisbaena vermicularis a redução é bastante acentuada e apenas um vestígio do pulmão direito, localizado látero-dorsalmente à porção caudal
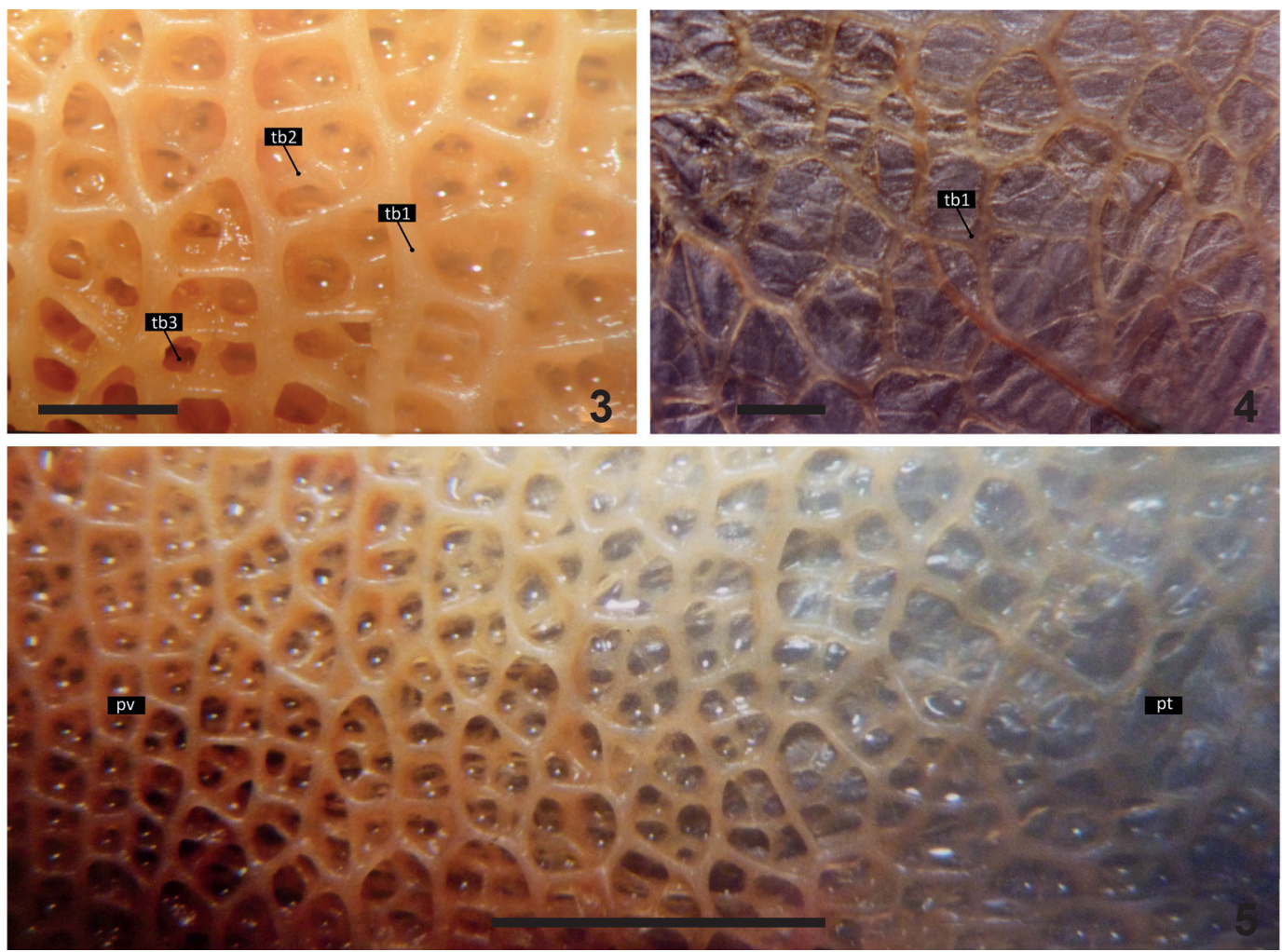

Figs 3-5. Amphisbaena microcephala (Wagler, 1824), pulmão esquerdo em seç̧ão longitudinal: 3, porção cranial com parênquima faveolar; 4, porção caudal com parênquima trabecular; 5 , porção média com a transição do parênquima faveolar para o parênquima trabecular (pv, parênquima faveolar; pt, parênquima trabecular; tb1, trabécula primária; tb2, trabécula secundária; tb3, trabécula terciária). Escalas: Fig. 3, 0,91 mm; Fig. 4, 1,25 mm; Fig. 5, 2,5 mm. 
da traqueia, pôde ser observado. Em A. microcephala o pulmão direito, embora reduzido, é um órgão com limites definidos separado do pulmão esquerdo pela porção caudal da traqueia, com o qual se comunica através de dois orifícios circundados por cartilagem, sugerindo serem estas as vias de passagem do ar para o mesmo. A abertura cranial é menor que a caudal e o parênquima apresenta arranjo faveolar típico (Figs. 1, 2).

Morfologia microscópica. Três regiões histologicamente distintas podem ser caracterizadas no tubo que conduz o ar da cavidade oral até os pulmões, denominado macroscopicamente de traqueia. A primeira ou laringe é um curto segmento após a glote que possui em sua parede peças cartilaginosas hialinas irregulares, unidas entre si por tecido conjuntivo frouxo, que não formam anéis definidos. Um epitélio do tipo pseudo-estratificado prismático, com células ciliadas e células produtoras de muco (PAS positivo), reveste de forma predominante a face interna do segmento. O epitélio está apoiado sobre uma espessa lâmina própria de tecido conjuntivo frouxo, com cinco ou mais camadas de fibroblastos (Fig. 6).

A segunda e maior porção do tubo condutor do ar, ou traqueia propriamente dita, caracteriza-se pela presença de peças cartilaginosas em forma de ferradura, que fornecem sustentação ao tubo. A face dorsal do segmento em contato mais próximo com o esôfago não apresenta cartilagem. Três tipos de epitélios são observados: cúbico simples, pavimentoso simples e pseudoestratificado prismático com células ciliadas e produtoras de muco. Excetuando-se as células ciliadas, praticamente todas as demais células do revestimento traqueal produzem muco (PAS positivo). O epitélio cúbico simples e o epitélio pavimentoso simples revestem predominantemente áreas do tubo associadas às cartilagens de suporte. Nas áreas sem cartilagem predominam o epitélio pseudoestratificado ciliado. Os epitélios estão apoiados sobre delgada lâmina própria de tecido conjuntivo frouxo, que se confunde com o pericôndrio. A cartilagem é do tipo hialina com matriz basófila mais densamente corada ao redor dos condrócitos, que se encontram retraídos na matriz. O revestimento externo da traqueia ou camada serosa é composto por mesotélio sobre espessa camada de tecido conjuntivo frouxo, vascularizado. Na região em que a traqueia está em contato com o esôfago há uma camada adventícia que une estes órgãos (Fig. 7).

A terceira região é o segmento caudal do tubo condutor do ar, ou brônquio, localizado entre os pulmões e que penetra no pulmão esquerdo. À medida que entra em contato com os tecidos pulmonares, o brônquio torna-se mais vascularizado e sofre redução gradativa do tecido cartilaginoso que o sustenta (Figs. 8-11). O revestimento epitelial é o mesmo descrito para a traqueia, no entanto, os capilares sanguíneos são abundantes sob as células epiteliais das áreas sem cartilagem e, mesmo nas áreas com cartilagem, os capilares estão presentes (Fig. 11). Finalmente, o lúmen bronquial funde-se ao lúmen pulmonar pelo desaparecimento dos tecidos que delimitam o brônquio, dando lugar às trabéculas que formam o parênquima pulmonar (Fig. 9).

$\mathrm{Na}$ margem das trabéculas primárias, em contato com o lúmen pulmonar, observam-se conjuntos de

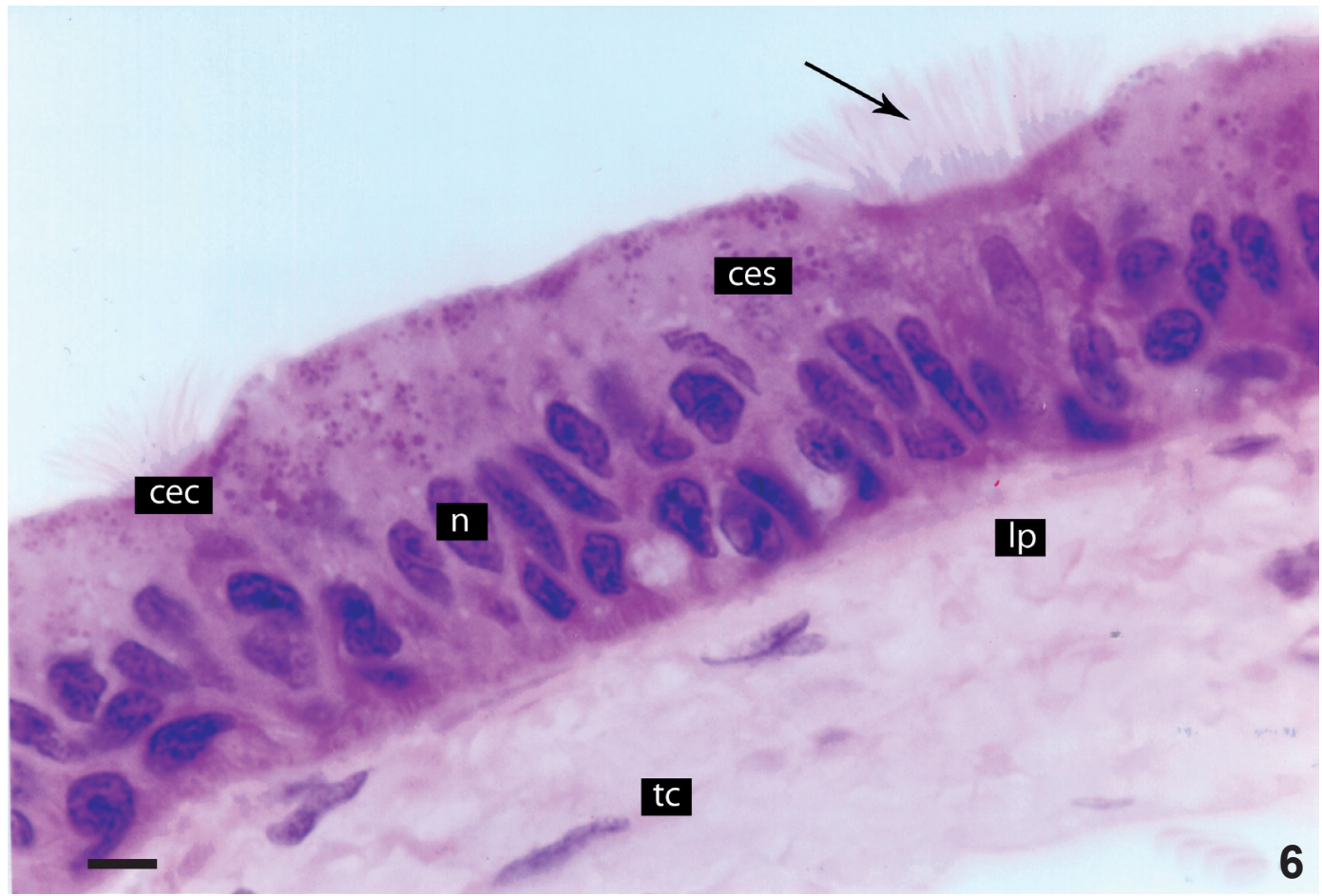

Fig. 6. Amphisbaena microcephala (Wagler, 1824), laringe em corte histológico transversal (ces, célula epitelial secretora; cec, célula epitelial ciliada; lp, lâmina própria; n, núcleo; tc, tecido conjuntivo). A seta indica os cílios das células epiteliais ciliadas. Coloração: toluidina/fucsina. Escala: $5 \mu \mathrm{m}$. 


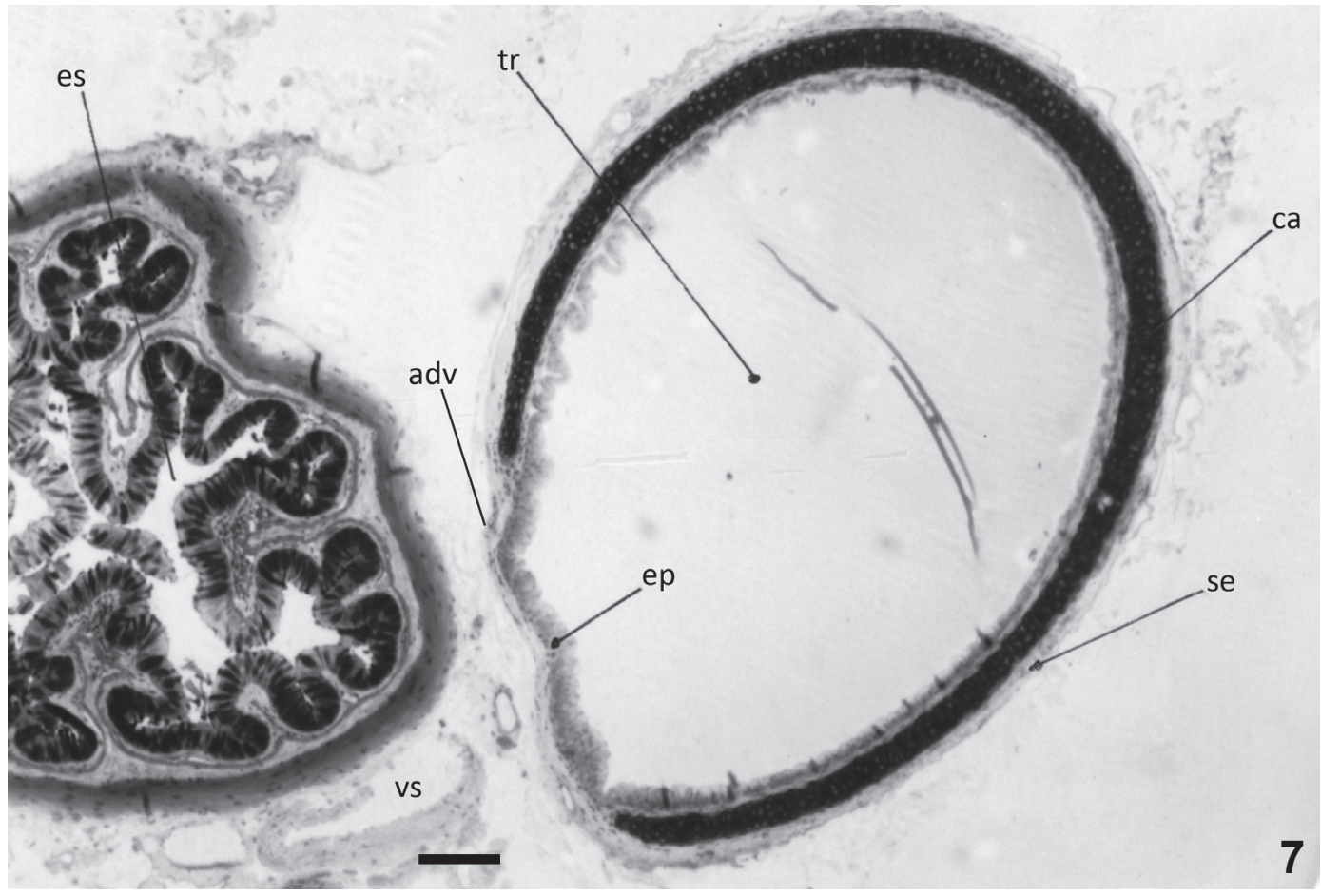

Fig. 7. Amphisbaena microcephala (Wagler, 1824), traqueia e esôfago em corte histológico transversal (adv, adventícia; ca, cartilagem; ep, epitélio; es, esôfago; se, serosa; tr, traqueia; vs, vaso sanguíneo). Escala: $100 \mu \mathrm{m}$.
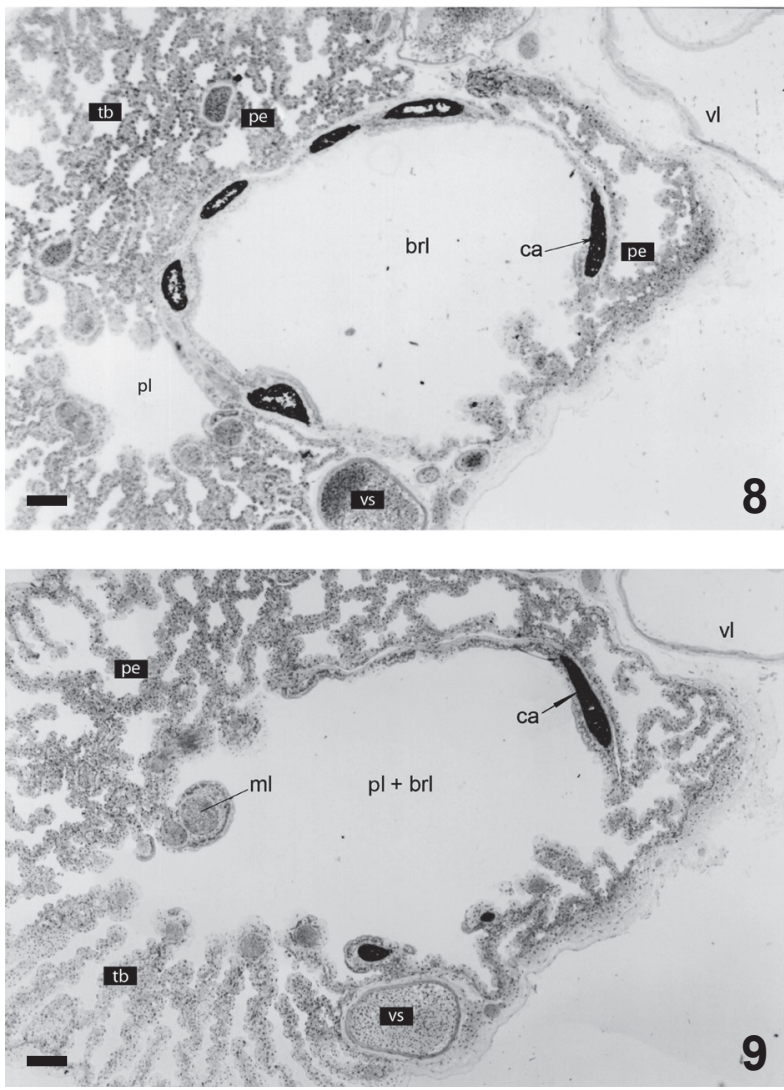

Figs 8, 9. Amphisbaena vermicularis Wagler, 1824, porção cranial do pulmão esquerdo em corte histológico transversal na altura do brônquio: 8 , brônquio; 9 , vestígio do brônquio e fusão do lúmen bronquial e pulmonar (brl, lúmen bronquial; ca, cartilagem; ml, músculo liso; pe, pulmão esquerdo; pl, lúmen pulmonar; tb, trabéculas pulmonares; vl, vaso linfático; vs, vaso sanguíneo). Escalas: $100 \mu \mathrm{m}$.
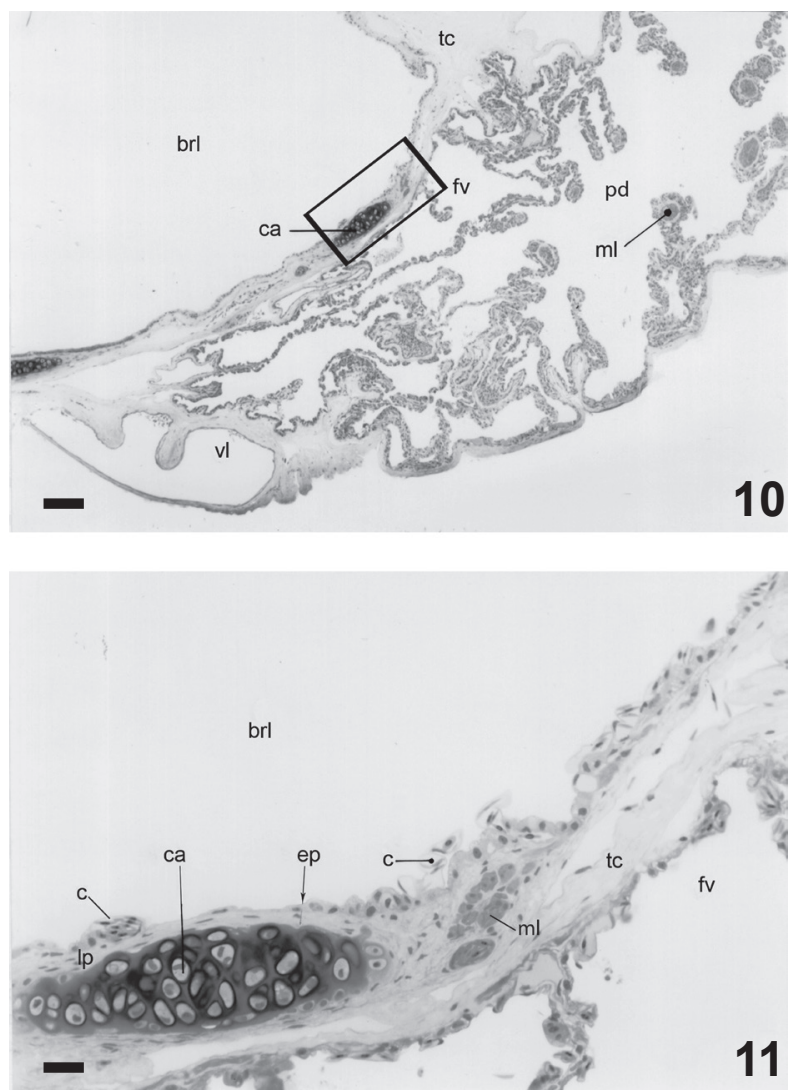

Figs 10, 11. Amphisbaena microcephala (Wagler, 1824), pulmão direito em corte histológico transversal: 10, pulmão direito e brônquio; 11 , detalhe do brônquio (brl, lúmen bronquial; c, capilar; ca, cartilagem; ep, epitélio; fv, favéolo; lp, lâmina própria; ml, músculo liso; pd, pulmão direito; tc, tecido conjuntivo frouxo; vl, vaso linfático). Escalas: $100 \mu \mathrm{m}, 25 \mu \mathrm{m}$. 
músculos lisos arranjados em forma de pacotes. Estes são revestidos predominantemente por epitélio pseudoestratificado prismático com células ciliadas e células produtoras de muco (PAS positivo), sendo as células ciliadas abundantes (Fig. 12). Pacotes menores de músculos lisos são encontrados também nas margens de algumas trabéculas secundárias e terciárias, porém no revestimento destas não se encontram células ciliadas, nem produtoras de muco. Capilares são abundantes sob o epitélio que reveste as trabéculas.

Ao longo do eixo de cada trabécula, que forma uma câmara respiratória, encontra-se uma delgada camada de tecido conjuntivo frouxo, com uma ou duas camadas de fibroblastos e fibras colágenas. Células musculares lisas também estão presentes ao longo de todo o eixo da trabécula, assim como vênulas e arteríolas preenchidas por eritrócitos (Fig. 13).

O revestimento epitelial do pulmão é predominantemente respiratório. Dois tipos de células revestem as câmaras faveolares: células pavimentosas ou pneumócitos tipo I e, células piramidais secretoras com aspecto vacuolizado, cuja morfologia é compatível com os pneumócitos tipo II. Um grande número de capilares preenchidos por eritrócitos está presente sob as células de revestimento (Fig. 13).
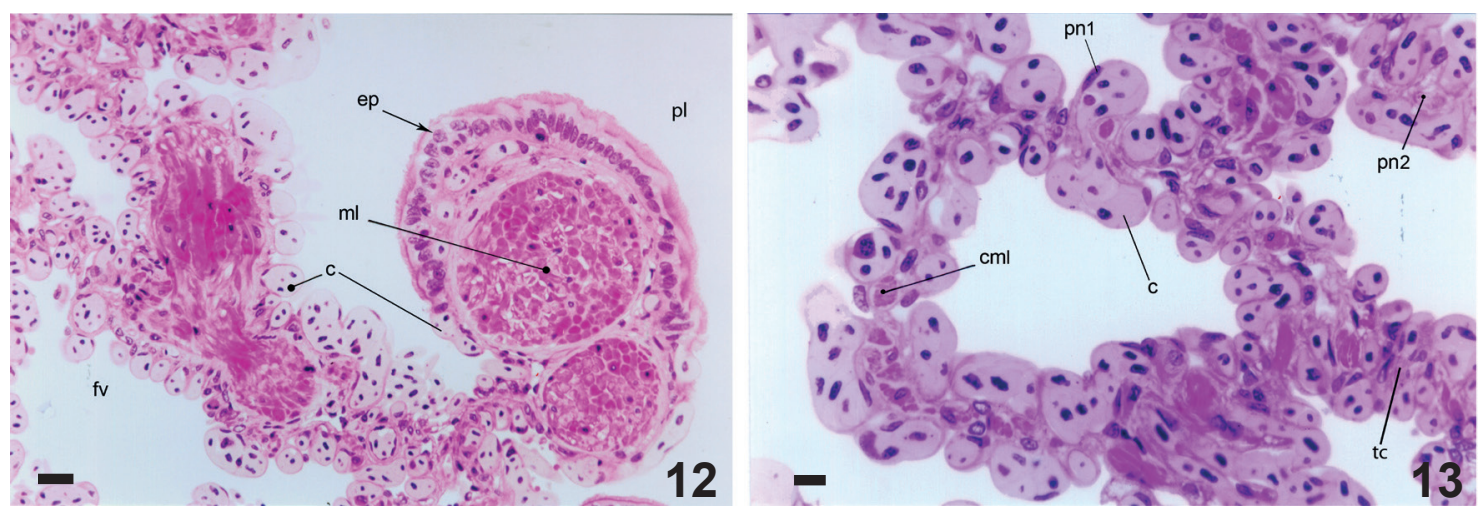

Figs 12,13. Amphisbaena vermicularis Wagler, 1824, porção cranial do pulmão esquerdo em corte histológico transversal: 12, detalhe dos músculos nas margens de uma trabécula primária; 13, detalhe das câmaras respiratórias (c, capilar; cml, célula muscular lisa; ep, epitélio pseudoestratificado prismático com células ciliadas e células produtoras de muco; fv, favéolo; pl, lúmen pulmonar; pn1, pneumócito tipo I; pn2, pneumócito tipo II; ml, músculo liso; tc, tecido conjuntivo). Coloração: toluidina/fucsina. Escalas: $25 \mu \mathrm{m}, 10 \mu \mathrm{m}$.
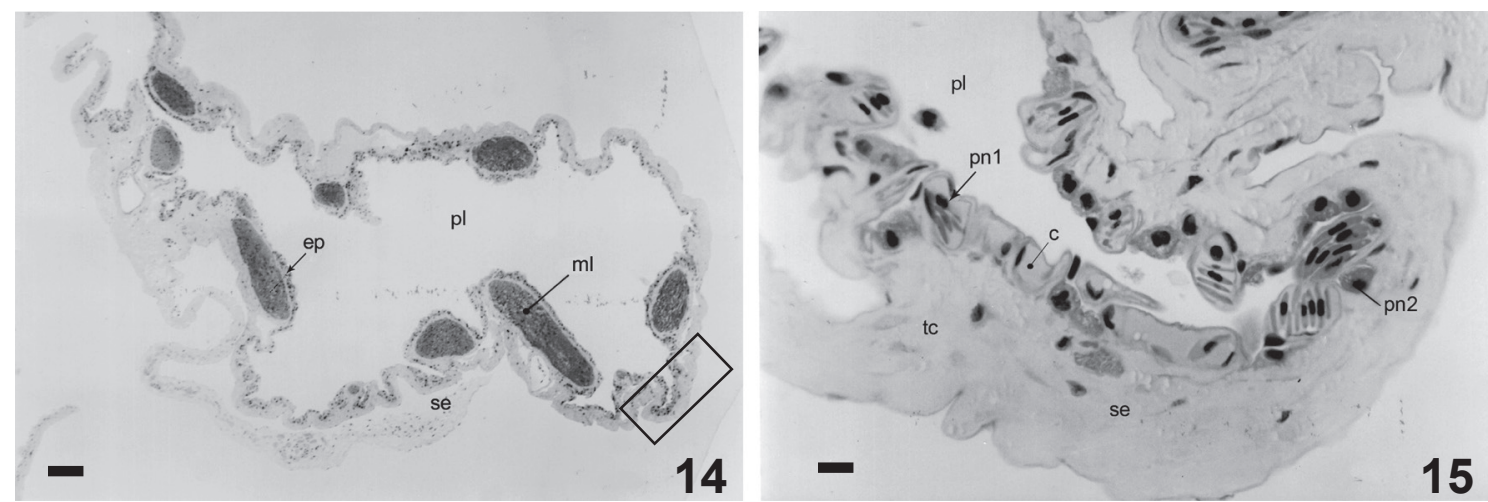

Figs 14,15. Amphisbaena microcephala (Wagler, 1824), porção caudal do pulmão esquerdo em corte histológico transversal: 14, parênquima trabecular; 15, detalhe da parede (c, capilar; ep, epitélio; pl, lúmen pulmonar; pn1, pneumócito tipo I; pn2, pneumócito tipo II; ml, músculo liso; se, serosa; tc, tecido conjuntivo frouxo). Escalas: $10 \mu \mathrm{m}, 100 \mu \mathrm{m}$. 
Ultraestrutura das câmaras respiratórias. As câmaras respiratórias apresentam dois tipos de células de revestimento: os pneumócitos tipo I e os pneumócitos tipo II (Figs 16-18). O pneumócito tipo I ou célula epitelial de revestimento é tipicamente achatada, de formato irregular com núcleo alongado, basal e heterocromático. Apresenta um grande número de vesículas de pinocitose em seu interior. O citoplasma é espesso ao redor do núcleo e delgado nas outras regiões da célula (Fig. 17). O pneumócito tipo II possui formato arredondado a cuboidal. O núcleo é grande e central, com a heterocromatina bem distribuída e o nucléolo evidente. $\mathrm{O}$ citoplasma apresenta muitos grânulos e corpos lamelares elétron-densos. Estes últimos são responsáveis pelo aspecto vacuolizado do citoplasma observado sob microscopia de luz. A superfície apical da célula possui muitos microvilos (Figs 16, 18).

Um tipo celular grande de formato arredondado e contendo muitos grânulos elétron-densos no citoplasma foi observado entre as células de revestimento. O núcleo é oval, basal e com eucromatina predominante. A presença discreta de corpos lamelares em seu interior sugere que esta célula possa ser um pneumócito tipo II em estágio imaturo (Fig. 18).

Os capilares pulmonares estão localizados sob a camada epitelial e são constituídos de células endoteliais pavimentosas típicas que possuem citoplasma espesso na região perinuclear e delgado nas outras regiões da célula. $\mathrm{O}$ núcleo é alongado com eucromatina e heterocromatina periférica, em proporções equivalentes. As células endoteliais também apresentam inúmeras vesículas de pinocitose em seus respectivos citoplasmas e membranas plasmáticas. No interior dos capilares, observam-se eritrócitos (Figs 16, 17).

As lâminas basais das células epiteliais (pneumócitos tipo I) e das células endoteliais encontram-se fundidas (Fig. 17). As extensões citoplasmáticas da célula epitelial e da célula endotelial e suas respectivas lâminas basais fundidas constituem a barreira entre o ar e o sangue, que é de aproximadamente $0,5 \mathrm{~mm}$ de espessura (medida em um espécime de Amphisbaena microcephala).

Entre duas câmaras respiratórias adjacentes foram observadas células musculares lisas e fibrócitos, sob as células de revestimento epitelial. A célula muscular lisa possui citoplasma elétron-denso e núcleo com heterocromatina em sua periferia. O fibrócito apresenta citoplasmaescasso, elétron-densoecompoucasorganelas. O núcleo é grande, com heterocromatina predominante na periferia do mesmo. Muitas fibras colágenas, imersas na matriz extracelular, foram observadas cortadas transversalmente e longitudinalmente, com suas típicas estriações periódicas (Figs 16, 18). Complexos juncionais tipo "tight" unem as células adjacentes.

\section{DISCUSSÃO}

O presente estudo mostrou que o pulmão esquerdo de Amphisbaena microcephala e de A. vermicularis são
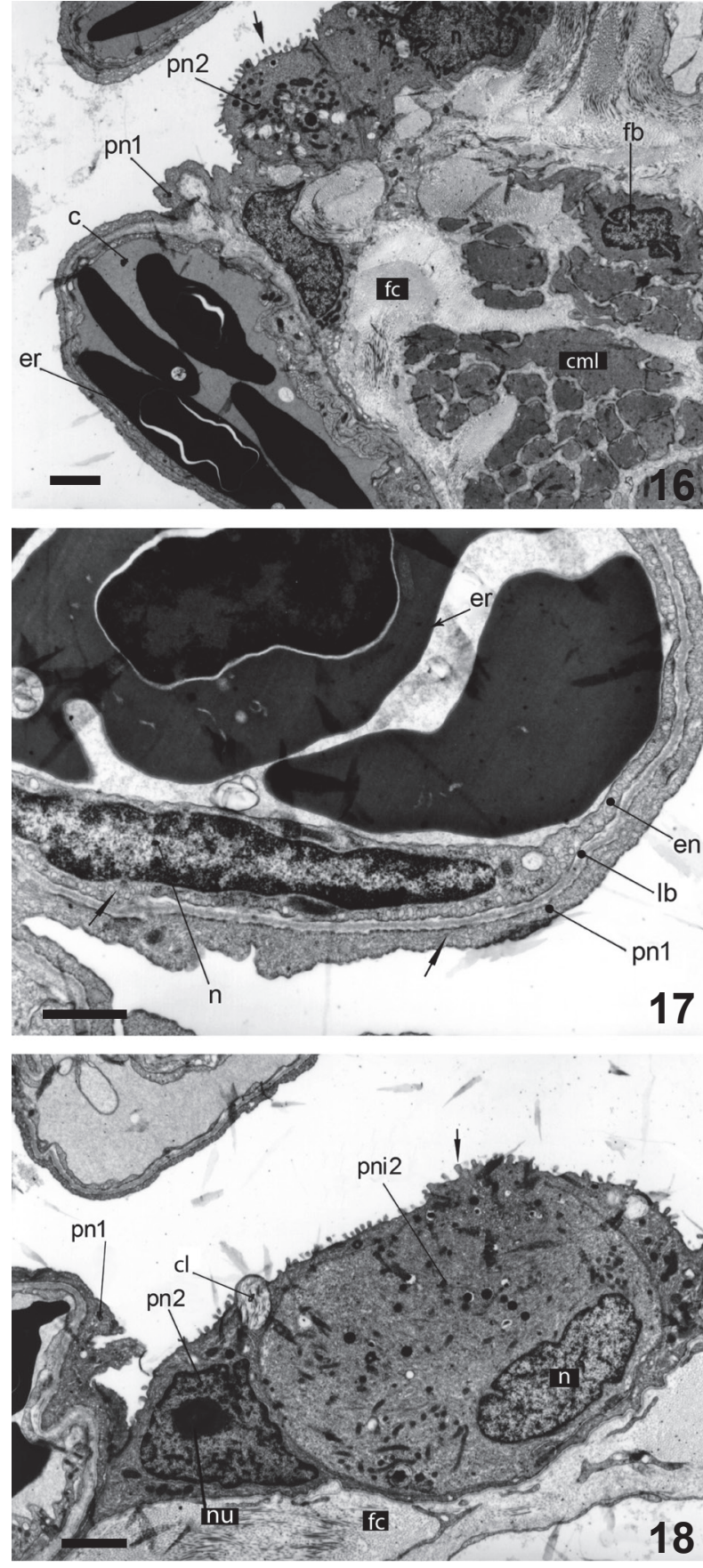

Figs 16-18. Amphisbaena microcephala (Wagler, 1824), câmaras respiratórias em microscopia eletrônica (c, capilar; cl, corpo lamelar; cml, célula muscular lisa; en, endotélio; er, eritrócito; fb, fibrócito; fc, fibras colágenas; lb, lâminas basais fundidas; pn1, pneumócito tipo I; pn2, pneumócito tipo II; pni2, pneumócito tipo II imaturo; n, núcleo; nu; nucléolo). As setas indicam os microvilos na superfície das células e as vesículas de pinocitose no interior. Escalas: $2 \mu \mathrm{m}, 1 \mu \mathrm{m}, 2 \mu \mathrm{m}$.

do tipo unicameral conforme descrição de DUNCKER (1978), com arranjo hierárquico de trabéculas primárias, secundárias e terciárias (GuIBÉ, 1970) descrito também para outros Squamata como os lagartos Tupinambis nigropunctatus Spix, 1825 (KLEMm et al., 1979) e Rhacodactylus leachianus (Cuvier, 1829) (PERrY et al., 1989) e a serpente Crotalus viridis oreganus Holbrook, 1840 (LUCHTEL \& KARDONG, 1981). O parênquima é 
do tipo faveolar na região cranial e trabecular na região caudal, o que caracteriza um pulmão heterogeneamente subdividido. Esse padrão é também encontrado em lagartos teídeos, lacertídeos e sincídeos e em serpentes (PERRY, 1983). A redução da espessura da parede do pulmão na região caudal do mesmo, observada nos anfisbenídeos citados, deve-se provavelmente à perda de trabéculas secundárias e terciárias a julgar pelo tamanho das trabéculas restantes e pelas grandes dimensões dos pacotes musculares, que permanecem em contato com o lúmen pulmonar.

A despeito da redução do número de trabéculas e da perda de favéolos na parede da região caudal do pulmão esquerdo, há muitos capilares evidenciando sítios de trocas gasosas, o que indica que os pulmões de Amphisbaena vermicularis e de A. microcephala podem ser considerados inteiramente funcionais para as trocas gasosas. O mesmo não acontece em serpentes, cuja região caudal do pulmão direito (o esquerdo é menor, reduzido ou ausente), ou região sacular, como é comumente designada, não tem função respiratória (LUCTHEL \& KARDONG, 1981). Outras funções, no entanto, têm sido atribuídas à região sacular do pulmão de serpentes, que poderia funcionar principalmente como um reservatório de ar (VARDE, 1951; BrattSTROM, 1959). Foi sugerido que o ar inspirado, após passar pela região vascularizada, fluiria para a região sacular retornando novamente para a porção cranial vascularizada aumentando, desta forma, as chances de trocas gasosas em cada ciclo respiratório (Brattstrom, 1959). Aumentando o fluxo total de ar, o déficit em volume seria compensado (McDonald, 1959). A região sacular poderia também agir como um fole na retirada do ar do parênquima pulmonar, quando a região cranial do corpo estivesse ocupada com outras funções e, não disponível para comprimir ou expandir o pulmão, como acontece, por exemplo, quando o alimento está sendo engolido (KARDONG, 1998). Com base nestas informações, é possível inferir que a região caudal do pulmão esquerdo em espécies de Amphisbaenia tenha outra função, além da respiratória, que justifique a redução parenquimática. Neste caso, poderia atuar também como um reservátorio de ar, compensando a baixa disponibilidade de oxigênio verificada nos ambientes subterrâneos onde vivem estes animais (Johansen et al., 1980; Kamel \& Gatten, 1983; Abe \& JOHANSEN, 1987).

A redução do diâmetro do corpo em relação ao comprimento do mesmo favorece o hábito fossorial e pode levar à redução unilateral de órgãos pares (GANS, 1975), como os pulmões, que ocupam um considerável espaço na cavidade pleuroperitoneal. No entanto, há diferentes graus de redução do pulmão direito entre as espécies de Amphisbaenia observadas (GANs, 1960; Crook \& Parsons, 1980; Navega-Gonçalves, 2009), sugerindo que outros fatores possam estar relacionados ao tamanho do mesmo nas diferentes espécies, como as modificações associadas à escavação (GANS, 1978,
NaVEGa-GonÇalves, 2009). Mesmo sendo reduzido, o pulmão direito de Amphisbaena microcephala, que equivale em média a $9,2 \%$ do pulmão esquerdo em comprimento (NAVEGA-GonÇALVES, 2009), apresenta morfologia compatível com a realização de trocas gasosas. O mesmo não pode ser afirmado para $A$. vermicularis, cujo pulmão resquicial (não mensurado no estudo realizado por NAVEGA-GonÇALVES, 2009) possui área respiratória demasiadamente reduzida. Em algumas serpentes, os pulmões reduzidos apresentam uma extensa rede de capilares, aparentemente envolvida com a respiração (KARDONG, 1972a).

A redução ou perda do pulmão direito em Amphisbaenia (BUTLER, 1895) provavelmente levou à perda da ramificação da traqueia em dois brônquios, como é observado também em serpentes que apresentam perda ou redução pulmonar (KARDONG, 1972a,b). Desta forma, o uso dos termos "traqueia" e "brônquios" são, nestes casos, arbitrários quando a observação se restringe ao âmbito macroscópico. $\mathrm{O}$ termo brônquio foi atribuído ao curto segmento do tubo condutor do ar, que se localiza entre os dois pulmões tanto em Amphisbaena vermicularis como em A. microcephala em virtude das modificações observadas com relação à redução do tecido cartilaginoso e consequente aumento na vascularização.

Em Amphisbaena microcephala, as duas aberturas que fazem a comunicação do brônquio com o pulmão direito estão em contato direto com os favéolos e são a única via de entrada de ar para o pulmão direito, uma vez que o mesmo não se comunica diretamente com o pulmão esquerdo. No anfisbenídeo Aulura anomala Barbour, 1914 apenas um orifício faz a comunicação entre o pulmão direito reduzido e o tubo traqueal (NAVEGAGonÇALVES, 2009), bem como em Amphisbaena alba Linnaeus, 1758 (MilanI, 1894). De acordo com WALLACH (1998), em serpentes a traqueia torna-se um brônquio na entrada do pulmão esquerdo atrofiado. Ou seja, a traqueia termina e o brônquio tem início ao nível do orifício que se abre no pulmão atrofiado. $\mathrm{O}$ conceito de Wallach (1998) pode ser aplicado para definir os limites entre a traqueia e o brônquio em $A$. microcephala, A. anomala e $A$. alba, mas não em $A$. vermicularis, cujo pulmão direito é rudimentar e não apresenta orifício que o comunica com o tubo traqueal. Neste caso e nas demais espécies em que o pulmão direito está ausente ou é muito reduzido, a delimitação do brônquio só poderia ser feita microscopicamente.

O epitélio traqueal foi descrito para poucas espécies de répteis e entre as espécies de lagartos e serpentes estudados, as células ciliadas e as células secretoras estão presentes em quantidades diferentes no mesmo. Tesik (1984) observou que as células secretoras são abundantes no epitélio traqueal dos lacertídeos Lacerta agilis Linnaeus, 1758 e Lacerta vivipara Jacquin, 1787 enquanto as células ciliadas aparecem em menor número. No geconídeo Rhacodactylus leachianus, as 
células ciliadas não são frequentes na traqueia (PERRY et al., 1989). Na serpente Natrix maura Linnaeus, 1758, estas células foram quantificadas mostrando uma razão de 30-40 células ciliadas para 160-170 células secretoras (PASTOR, 1990). Embora as mesmas não tenham sido quantificadas nos anfisbenídeos aqui estudados, é notável o predomínio das células secretoras em relação às células ciliadas na laringe e na traqueia.

De acordo com PERRY et al. (1989), a presença de grande quantidade de células secretoras na traqueia poderia aumentar a umidificação do ar inalado e exalado e, deste modo, diminuir a probabilidade de perda de umidade através do epitélio pulmonar. Para os anfisbênios é provável que tanto as células mucosas como as ciliadas contribuam também para a remoção de partículas em suspensão encontradas nas galerias subterrâneas, onde vivem estes animais, uma vez que os atos de escavação e de locomoção dentro dos túneis provocam o movimento de partículas do solo. A superfície pulmonar, que é continuamente exposta ao ar atmosférico, é mantida limpa através da ação de células mucosas e ciliadas, que em pulmões primitivos intercalam-se às células envolvidas com as trocas gasosas (LiEM, 1988). As células mucosas agiriam na umidificação do ar inspirado e na captura de partículas estranhas, que seriam removidas pelos movimentos ciliares das células ciliadas deixando as superfícies de trocas gasosas livres de qualquer obstrução (KLEMM et al.,1979; LuCTHEL \& KARDONG,1981). Da mesma forma como mencionado para o epitélio traqueal, as células mucosas e ciliadas nos pulmões dos anfisbenídeos examinados teriam particular importância na remoção de partículas das superfícies respiratórias, que são constantemente expostas ao ar das galerias subterrâneas.

Os pacotes musculares nas margens das trabéculas pulmonares dos anfisbenídeos estudados poderiam promover uma mudança no diâmetro das aberturas dos favéolos, assim como têm sido sugerido para lagartos e serpentes (LuCHTEL \& KARDONG, 1981), sustentando os mesmos abertos durante a variação nos estágios de inflação dos pulmões (DunCKER, 1978; Perry \& DUNCKER, 1978). A contração dos músculos lisos das trabéculas, ao provocar o estreitamento do lúmen pulmonar, tornaria os favéolos alongados promovendo um mecanismo ventilatório intrapulmonar, fazendo com que o ar se movesse em direção às superfícies respiratórias (KLEMm et al., 1979).

Em répteis, a ultraestrutura das câmaras respiratórias foi descrita primeiramente nas serpentes Elaphe climacophora (Boie, 1826) e Elaphe quadrivirgata (Boie, 1826) e no geconídeo Gekko japonicus (Schlegel, 1836) (ОкаDA et al., 1962; NAGAISHI et al., 1964). Naqueles estudos, os pneumócitos I e II foram identificados como célula epitelial alveolar e célula da parede alveolar, respectivamente. Os pneumócitos tipo I e II descritos em Amphisbaena vermicularis e A. microcephala e em outras espécies de
Squamata estudadas (MeBAn, 1978; KLEmm et al., 1979; Luchtel \& Kardong, 1981; Pohunková \& Hudges, 1985; Perry et al., 1989) são similares às mesmas células conhecidas em mamíferos (NAGAISHI et al., 1964; WeIBEL, 1973).

Os pneumócitos I e as células endoteliais possuem suas membranas basais fundidas diminuindo, desta forma, a barreira para a realização das trocas gasosas entre o ar e o sangue, que é de aproximadamente 0,5 mm em um espécime de Amphisbaena microcephala examinado. Espécies de lagartos e serpentes também possuem as membranas basais das células citadas fundidas e a barreira ar-sangue apresenta valores variados entre as mesmas: $0,3 \mathrm{~mm}$ em Elaphe climacophora e Elaphe quadrivirgata (ОKADA et al., 1962); 0,4 a $0,6 \mathrm{~mm}$ em Crotalus viridis oreganus (LuCHTEL \& KaRdONG, 1981); 0,1 mm em Gekko japonicus (OKaDA et al., 1962); 0,5 a 0,6 $\mathrm{mm}$ em Rhacodactylus leachianus (PERRY et al., 1989) e 0,7 a 1,0 mm em Tupinambis nigropunctatus (KLEMm et al., 1979). Alguns destes valores são semelhantes ao reportados para aves $(0,1$ mm) (NAGAishi et al., 1964) e mamíferos (0,3 a 0,5 mm) (WeIBEL, 1973).

A forma característica do pneumócito tipo I pode ser associada à sua função, onde a porção perinuclear, com citoplasma espesso, encarrega-se da nutrição celular, enquanto a delgada extensão citoplasmática incumbe-se das trocas gasosas (NAGAISHI et al.,1964). Os pneumócitos tipo II estão provavelmente envolvidos com a síntese de surfactante pulmonar (SOROKIN, 1967; Kunn, 1968; Meban, 1972). Este tipo celular é encontrado tanto em pulmões primitivos como nas formas avançadas, porque a produção de fluido surfactante é essencial na proteção das delicadas células epiteliais e na redução da tensão superficial, evitando que as paredes das câmaras respiratórias colapsem (LIEM, 1988). O surfactante pulmonar poderia ainda prevenir a adesão de muco sobre o epitélio ciliado (Allegra et al., 1985) ou agir como um agente anti-edema, nos pulmões de répteis, prevenindo possíveis hemorragias nas câmaras respiratórias (SMITs et al., 1995).

Os pulmões de répteis apresentam grande diversidade de estruturas e funções que pode estar relacionada a um modo de vida peculiar da espécie (Pohunková \& Hugdes, 1985). Sendo assim, os anfisbênios, que são répteis fossoriais, possuem órgãos respiratórios que devem garantir a eficiência das trocas gasosas a variadas profundidades no solo, sob condições diferentes das encontradas na superfície, como mostram alguns dos estudos realizados.

Foi demonstrado que Amphisbaena alba quando comparada com outros répteis, apresenta maior afinidade sanguínea ao oxigênio (JoHANSEN et al., 1980) e que seus músculos esqueléticos e cardíacos revelam alta concentração de mioglobina, que pode ser atribuída à atividade muscular (escavação e predação), assim como em resposta às condições de hipóxia e hipercapnia, que 
poderiam prevalecer nos túneis (WeBer et al.,1981). A tomada de $\mathrm{O}_{2}$ por $A$. alba é consideravelmente mais baixa quando comparada aos valores reportados para lagartos e serpentes de pesos equivalentes, sugerindo uma adaptação para a vida fossorial. A espécie citada realiza também uma parcela das trocas gasosas através da pele, ou seja, $20 \%$ do volume total de $\mathrm{O}_{2}$ e mais que $43 \%$ das trocas de $\mathrm{CO}_{2}$ ocorrem por esta via (ABE \& JOHANSEN, 1987).

O anfisbênio Trogonophis wiegmanni Kaup, 1830 apresenta baixo metabolismo em situação de repouso, o que poderia ser vantajoso em habitat subterrâneo, devido às baixas concentrações de $\mathrm{O}_{2}$ (KAMEL \& Gatten, 1983). Navas et al. (2004) demonstraram em Amphisbaena microcephala que os músculos envolvidos nos movimentos craniais durante a atividade de escavação apresentam acentuada capacidade oxidativa e um evidente aumento na concentração de mioglobina.

Dentre as principais características morfológicas do sistema respiratório de Amphisbaena vermicularis e A. microcephala podem ser citadas o pulmão esquerdo muito alongado, que funciona como reservatório de ar, contendo uma região cranial com parênquima altamente vascularizado e densamente subdividido em câmaras respiratórias e uma região caudal que realiza trocas gasosas; e o pulmão direito funcional em A. microcephala, apesar de reduzido. Essas características nos levam a acreditar na hipótese de que as especializações fisiológicas conhecidas aliadas às características morfológicas descritas neste estudo estão entre as adaptações que permitem a sobrevivência dos Amphisbaenia em galerias no solo, onde passam a maior parte de suas vidas sob condições de baixa renovação do ar, umidade relativa variável e partículas em suspensão.

Agradecimentos. A Gaspar Ferreira de Lima e Edson Rocha de Oliveira, pelas preparações ultraestruturais e pelo suporte fotográfico das mesmas e a Camila Navega Gonçalves pelo tratamento das imagens; ao Departamento de Histologia e Embriologia do ICBUSP, por permitir a realização de parte deste estudo e o acesso à microscopia; a Ana Maria de Souza, pela orientação deste estudo e ao $\mathrm{CNPq}$ pelo financiamento à primeira autora durante o Doutoramento realizado no Departamento de Zoologia do IB-USP.

\section{REFERÊNCIAS BIBLIOGRÁFICAS}

Abe, A. S. \& Johansen, K. 1987. Gas exchange and ventilatory responses to hypoxia and hypercapnia in Amphisbaenia alba (Reptilia: Amphisbaenia). Journal of Experimental Biology 127:159-172.

Allegra, L.; Bossi, R. \& Braga, P. 1985. Influence of surfactant on mucociliary transport. European Journal Respiratory Deseases 142:71-76.

Bedriaga, J. V. 1884. Amphibaena cinerea Vand. und A. strauchi v. Bedr. erster beitrag zur kenntniss der Doppelschleichen. Archiv für Naturgeschichte 50(1):23-77.

Brattstrom, B. H. 1959. The functions of the air sac in snakes. Herpetologica 15:103-104.

ButLer, G. W. 1895. On the complete or partial suppression of the right lung in the Amphisbaenidae and of the left lung in snakes and snake-like lizards and amphibians. Proceedings of the Zoological Society of London 1895:691-712.

COOPER, J. E. 1992. Anaesthesia of exotic species. In: HiLBERY, A. D. R. ed. Manual of anaesthesia for small animal practice. Cheltenham, British Small Animal Veterinary Association, p. 139-151.

Crook, M. J. \& Parsons, T. 1980. Visceral anatomy of the Amphisbaenia. Journal of Morphology 163:99-133.

DunCKER, H. R. 1978. General morphological principles of amniotic lungs. In: PIPPER, J. ed. Respiratory function in birds, adult and embryonic. Heidelberg, Springer Verlag, p. 2-15.

Gans, C. 1960. Studies on amphisbaenids (Amphisbaenia, Reptilia). 1. A taxonomic revision of the Trogonophidae, and a functional interpretation of the amphisbaenid adaptative pattern. Bulletin of the American Museum of Natural History 119:129-204.

1968. Relative sucess of divergent pathways in amphisbaenian specialization. The American Naturalist 102(926):345-362.

1975. Tetrapod limblessness: evolution and functiona corollaries. American Zoologist 15(2):455-467.

1978. The characteristics and affinities of the Amphisbaenia. Transactions of the Zoological Society of London 34:347-416.

GuibÉ, J. 1970. L'appareil respiratorie. In: Grassé, P. P. ed. Traité de Zoologie: anatomie, systematique, biologie. Paris, Masson. v. 14 , fasc. 2, p. 499-520.

Hayat, M. T. 1981. Fixation for electron microscopy. London, Academic Press. 437p.

JohANSEn, K.; Abe, A. S. \& Weber, R. E. 1980. Respiratory properties of whole blood and hemoglobin from the burrowing reptile, Amphisbaena alba. The Journal of Experimental Zoology 214:71-77.

JUNQUEIRA, L. C. U. 1995. Histology revisited - Techinical improvement promoted bye the use of hidrophilic resin embedding. Ciência e Cultura 47(1,2):92-95.

Kamel, S. \& GatTen, R. E. JR. 1983. Aerobic and anaerobic activity metabolism of limbless and fossorial reptiles. Physiological Zoology 56(3):419-429.

KARDONG, K. V. 1972a. Morphology of the respiratory system an its musculature in different snake genera. Part I Crotalus and Elaphe. Gegenbaurs Morphologishes Jahrbuch 117:285-302.

1972b. Morphology of the respiratory system an its musculature in different snake genera. Part II Charina bottae. Gegenbaurs Morphologishes Jahrbuch 117:364-376.

1998. Vertebrates: comparative anatomy, function, evolution. 2ed. Boston, WCB/McGraw-Hill. 747p.

Klemm, R. D.; Gatz, R. N.; Westfall, J. A. \& Fedde, M. R. 1979. Microanatomy of the lung parenchyma of a tegu lizard Tupinambis nigropunctatus. Journal of Morphology 161:257-280.

KunN, C. 1968. Cytochemistry of pulmonary alveolar epithelial cells. American Journal of Pathology 53(2):809-833.

LIEM, K. F. 1988. Form and function of lungs: The evolution of air breathing mechanisms. American Zoologist 28:739-759.

Luchtel, D. L. \& KardonG, K.V. 1981. Ultrastructure of the lung of the rattlesnake, Crotalus viridis oreganus. Journal of Morphology 169:29-47.

MASSONE, F. 1999. Anestesiologia veterinária: farmacologia e técnicas. 3ed. Rio de Janeiro, Guanabara Koogan. 252p.

MCDONALD, H.S. 1959. Respiratory functions of the ophidian air sac. Herpetologica 15:193-198.

McDowell, E. M. \& Trump, B. F. 1976. Histologic fixatives suitable for diagnostic light and electron microscopy. Archives of Pathology and Laboratory Medicine 100:405-414.

McManus, J. F. A. 1946. Oxidation of mucin with periodic acid Schiff's reagent. Nature 158:202.

Meban, C. 1972. A cytochemical study of the granular pneumonocytes in hamster lung. Journal of Anatomy 111(2):293-302.

1978. Functional anatomy of the lungs of the green lizard, Lacerta viridis. Journal of Anatomy 125(2):421-431.

MeCKel, J. F. 1818. Ueber das Respiratiossystem der Reptilien. Deutsches Archiv für die Physiologie 4:60-89.

MilanI, A. 1894. Beiträge zur Kenntnis der Reptilienlunge. I Lacertilia. Zoologische Jahrbücher Abteilung für anatomie und Ontogenie der Tiere 7:545-592.

Nagaishi, C.; OKada, Y.; Ishiko, S. \& Daido, S. 1964. Electron microscopic observations of the pulmonary alveoli. Experimental Medicine and Surgery 22:81-117

Navas, C. A.; Antoniazzi, M. M.; Carvalho, J. E.; Chaui-Berlink, J. G.; James, R. S.; JaRed, C.; Kohlsdorf, T.; PaI-Silva, M. D. \& WILSON R. S. 2004. Morphological and physiological specialization for digging in amphisbaenians, an ancient lineage of fossorial vertebrates. The Journal of Experimental Biology 207:2433-2441. 
Navega-Gonçalves, M. E. C. 2009. Anatomia visceral comparada de seis espécies de Amphisbaenidae (Squamata: Amphisbaenia). Zoologia 26(3):511-526.

Navega-Gonçalves, M. E. C. \& Souza, A. M. 2001. Anatomia visceral de Amphisbaena mertensi Strauch, 1881 (Reptilia, Amphisbaenia, Amphisbaenidae). Papéis Avulsos de Zoologia 41(26):489-518

OKADA, Y.; Ishiko, S.; DAIDO, S.; KIM, J. \& IKedA, S. 1962. Comparative morphology of the lung with special reference to the alveolar lining cells. II. Lung of the Reptilia. Acta Tuberculosea Japonica 12:1-10.

Pastor, L. M. 1990. A morphological study of the tracheal epithelium of the snake Natrix maura. Journal of Anatomy 172:47-57.

Perry, S. F. 1983. Reptilian lungs: functional anatomy and evolution. Advances in Anatomy Embryology and Cell Biology 79:1-81.

. 1998. Lungs: comparative anatomy, functional morphology, and evolution. In: Gans, C. \& Gaunt, A. S. eds. Biology of the Reptilia. Ithaca, New York, Society for the Study of Amphibians and Reptiles. v. 19, p. 2-92.

Perry, S. F. \& Duncker, H. R. 1978. Lung architecture, volume and static mechanics in five species of lizards. Respiration Physiology 34:61-81.

Perry, S. F.; Bauer, A . M.; Russel, A. P.; Alston, J. T. \& Maloney, J. E. 1989. Lungs of the gecko Rhacodactylus leachianus (Reptilia: Gekkonidae): A correlative gross anatomical and light and electron microscopic study. Journal of Morphology 199:23-40.
Pohunková, H. \& Hughes, G. M. 1985. Ultrastructure of the lungs of the garter snake. Folia Morphologica 33:254-258.

REYNOLDS, E. S. 1963. The use of lead citrate at high $\mathrm{pH}$ as an eletronicopaque stain in electron microscopy. Journal of Biophysical and Biochemical Cytology 17:208-213.

Smalian, C. 1884. Beiträge zur Anatomie der Amphisbaeniden. Zeitschrift für Wissenschaftliche Zoologie 42(1):126-202.

Smits, A.W.; Orgeig, S. \& DANIELS, C. B. 1995. Surfactant functions as an anti-edema agent in lungs of the lizard (Pogona vitticeps). The Faseb Journal 9(4):A861.

SorokIN, S. P. 1967. A morphologic and cytochemical study on the great alveolar cell. The Journal of Histochemistry and Cytochemistry 14(12):884-897.

TesIK, I. 1984. The ultrastructure of the tracheal epithelium in european common lizard (Lacerta agilis L.) and in sand lizard (Lacerta vivipara Jacq.). Anatomischer Anzeiger 155:329-340.

VARDE, M. R. 1951. The morphology and histology of the lung in snakes. Journal of the University of Bombay 19:79-89.

Wallach, V. 1998. The lungs of snakes. In: Gans, C. \& Gaunt, A. S. eds. Biology of the Reptilia. Ithaca, New York, Society for the Study of Amphibians and Reptiles. v. 19, p. 93-295.

Weber, R. E.; Johansen, K. \& Abe, A. S. 1981. Myoglobin from the burrowing reptile Amphisbaena alba. Concentrations and functional characteristics. Comparative Biochemistry and Physiology 68A:159-165.

Weibel, E. R. 1973. Morphological basis of alveolar-capilary gas exchange. Physiological Reviews 53(2):419-495. 